\title{
Heavy metal sources and associated risk in response to agricultural intensification in the estuarine sediments of Chaohu Lake Valley, East China
}

\author{
Wenzhong Tang a , Baoqing Shan ${ }^{\mathrm{a}, *}$, Hong Zhang ${ }^{\mathrm{a}}$, Zhanpo Mao ${ }^{\mathrm{b}}$ \\ a State Key Laboratory on Environmental Aquatic Chemistry, Research Center for Eco-Environmental Sciences, Chinese Academy of Sciences, \\ Shuangqing Road 18, Beijing 100085, China \\ ${ }^{\mathrm{b}}$ China Institute of Water Resources and Hydropower Research, Beijing 100044, China
}

\section{A R T I C L E I N F O}

\section{Article history:}

Received 17 June 2009

Received in revised form

25 November 2009

Accepted 25 November 2009

Available online 3 December 2009

\section{Keywords:}

Heavy metals

Estuarine sediments

Risk

Chaohu Lake

Agricultural intensification

\begin{abstract}
A B S T R A C T
In this study, the source and risk associated with heavy metals in the estuarine sediments of Chaohu Lake Valley in East China were studied. The results demonstrated that most metal contents ( $\mathrm{Cd}, \mathrm{Pb}$ and $\mathrm{Zn}$ ) increased continuously from $0.21,8.05$ and $73.76 \mathrm{mg} / \mathrm{kg}$ in the substrate to $0.33,17.20$ and $100.22 \mathrm{mg} / \mathrm{kg}$ in the surface sediments on average, respectively, in all ten estuaries evaluated. In addition, the high proportion of chemically reactive forms of $\mathrm{Cd}(18.10-33.60 \%)$ implied a moderately high risk, while the risk associated with $\mathrm{Pb}$ and $\mathrm{Zn}$ was moderate in most estuaries. Enrichment factor (EF) and cluster analysis (CA) were conducted to assess the metal sources. The $\mathrm{EF}$ values of $\mathrm{Cd}, \mathrm{Pb}$ and $\mathrm{Zn}(4.96,3.68$ and 2.25, respectively) indicated that they had accumulated in the estuarine sediments. Additionally, CA suggested that their primary sources were anthropogenic, namely the extensive use of fertilizers. Therefore, heavy metal pollution due to agricultural intensification in Chaohu Lake Valley should be taken into account during the formation of valley management strategies for the water environment.
\end{abstract}

(C) 2009 Elsevier B.V. All rights reserved.

\section{Introduction}

Heavy metal accumulation in sediments is a source of growing interest and concern; therefore, the fate of heavy metals in the water environment has recently been the subject of extensive discussion [1-4]. Sediments contaminated with heavy metals have been found to enter aquatic environments via several pathways, including atmospheric deposition, industrial activities and agricultural activities [5-8]. When compared with the previous two pathways, agricultural activities are known to be significant non-point sources of heavy metals in the environment $[9,10]$. Different methods, such as EF and CA, have been widely applied in investigations to identify pollution sources and to apportion natural vs. anthropogenic contributions [11-13]. Sedimentation processes usually occur during the subsequent transport of heavy metals from these anthropogenic sources to the surface and ground water [14]. Because they generally contribute low concentrations of heavy metals, agricultural activities have traditionally been neglected when conducting risk assessment. However, environmental problems due to long-term accumulation of heavy metals in agricultural regions have increased in recent years $[15,16]$. The distribution of heavy metals in sediments adjacent to populated areas can

\footnotetext{
* Corresponding author. Tel.: +86106284 9817; fax: +861062913541.

E-mail address: bqshan@rcees.ac.cn (B. Shan).
}

provide researchers with evidence of the anthropogenic impact on ecosystems and assist in assessing the risks associated with discharged human waste [17]. Therefore, problems in aquatic systems due to heavy metals pollution have been extensively studied [18-20].

Chaohu Lake Valley in East China has a traditional agriculturalbased economy and a centuries-old history of cultivation [21,22]. During the past few decades, agricultural cultivation in this area has intensified in response to a steady increase in population and the relative scarcity of land [23]. Increased agricultural activity involves the intensive use of fertilizers, which contain heavy metals such as $\mathrm{As}, \mathrm{Cd}, \mathrm{Hg}, \mathrm{Ni}, \mathrm{Pb}$ and $\mathrm{Zn}$; therefore, the continuous application of fertilizers and soil amendments can exacerbate the accumulation of heavy metals in agricultural regions [24-26]. Although determination of the risk associated with heavy metals accumulation within estuarine sediments in agricultural regions as a result of intensified agriculture is important to the formation of valley management strategies for the aquatic environment, this process is poorly understood.

This present study was conducted to evaluate ten estuaries located in the agricultural region of Chaohu Lake Valley to assess the contribution of emission sources to the pollution from local agricultural intensification. The specific goals of this study were (1) to investigate the risk associated with six heavy metals $(\mathrm{Cd}, \mathrm{Cr}, \mathrm{Cu}, \mathrm{Ni}$, $\mathrm{Pb}$ and $\mathrm{Zn}$ ) in sediments in the investigated area and (2) to analyze their lithogenic or anthropogenic origin by both EF and CA. 


\section{Materials and methods}

\subsection{Description of the study area}

Chaohu Lake $\left(30^{\circ} 58^{\prime}-32^{\circ} 06^{\prime} \mathrm{N}, 116^{\circ} 24^{\prime}-118^{\circ} 00^{\prime} \mathrm{E}\right)$, which is located in Anhui Province, East China, is the fourth largest freshwater lake in China. Chaohu Lake is a typical large, shallow, subtropical lake that covers an area of $780 \mathrm{~km}^{2}$ and has a mean water depth of $2.69 \mathrm{~m}$. The catchment is subject to a transitional subtropical to warm temperate monsoon climate. The annual average temperature and precipitation in the area are $16.1^{\circ} \mathrm{C}$ and $900.5 \mathrm{~mm}$, respectively. Because of the agricultural intensification that has been observed in recent decades, deterioration of the aquatic environment in Chaohu Lake Valley is becoming serious $[27,28]$.

This case study was conducted in all ten estuaries located in the agricultural region of Chaohu Lake Valley (Fig. 1), which are situated at the end of the Changlin, Qianxi, Liucha, Shengli, Huatang, Laoshu, Jiaozhi, Xiao, Baishan and Xin rivers (hereafter denoted as 1-10, respectively). The length of these rivers ranges from approximately 5 to $15 \mathrm{~km}$, and their width ranges from approximately 6 to $30 \mathrm{~m}$. All rivers are primary agricultural rivers in Chaohu Lake Valley. Land in the study area is primarily used for cultivation, which results in the estuaries being subject to non-point source inputs from agricultural activities [29]. Such characteristics result in spatial consistency at the landscape scale; therefore, they were deemed to result in a similar sedimentation processes among the estuaries. Moreover, many pollutants have accumulated in the estuarine sediments in recent years due to increased agricultural activity.

\subsection{Sample collection}

Estuarine sediments were collected in November 2007 at the ten stations (Fig. 1) using hand-held PVC corers with a diameter of $8 \mathrm{~cm}$ and a length of $150 \mathrm{~cm}$. Five sediment columns were collected at random from each station from areas in which the sediments had not been disturbed, and all columns were transected into $5 \mathrm{~cm}$ segments in sequence. The samples $(n=300)$ were initially collected into self-given bags. Upon arrival in the laboratory, the samples were air-dried to reduce the water content, after which they were transferred into an oven and dried at $40^{\circ} \mathrm{C}$. The samples were then ground to be able to pass through a 100-mesh sieve prior to analysis.

\subsection{Analytical methods}

The total phosphorus (TP) of the sediment samples was analyzed by the $\mathrm{HClO}_{4}-\mathrm{H}_{2} \mathrm{SO}_{4}$ digestion method [30]. For total heavy metal analysis, the sample was digested with a 5:1 mixture of hydrofluoric and perchloric acids [31]. The chemical reactive forms and the exchangeable and bound fractions were determined using the procedure described by Hlavay and Polyak [32]. All of the above solutions were stored at $4{ }^{\circ} \mathrm{C}$ prior to analysis. Inductively coupled plasma-mass spectrometry (ICP-MS) was used to determine the $\mathrm{Cd}$, $\mathrm{Cr}, \mathrm{Cu}, \mathrm{Ni}, \mathrm{Pb}$ and $\mathrm{Zn}$ concentrations. The recoveries varied, but all fell within the range of $90-95 \%$, and the precision was under $3 \%$ RSD (relative standard deviation).

\subsection{Enrichment factor}

To obtain information regarding the sources, changes with time and factors influencing the metals, the enrichment factors of metals in the estuarine sediments were calculated according to the equation generalized from Zhang and Shan [16] (Eq. (1)):

$\mathrm{EF}=\frac{\left[C_{\mathrm{n}(\text { sample })} / C_{\mathrm{Al}(\text { sample })}\right]}{\left[B_{\mathrm{n}(\text { baseline })} / B_{\mathrm{Al}(\text { baseline })}\right]}$

where $C_{\mathrm{n}}$ is the metal content in the sediments, $B_{\mathrm{n}}$ is the baseline concentration of the metal in sediment that has only been slightly impacted by human activities, especially the extensive use of fertilizers, $C_{\mathrm{Al}}$ is the $\mathrm{Al}$ concentration in the sediments and $B_{\mathrm{Al}}$ is the baseline concentration of Al. For this study, the metal concentrations of a reference plot in Chaohu Lake Valley were adopted as the baseline value.

\subsection{Statistical analysis}

The experimental data were analyzed using SPSS 13.0 for Windows. Spearman's correlation was used to assess the relationship between heavy metal contents and total phosphorus. A one-sample $t$-test $(p \leq 0.05)$ was used to analyze the variance. Multivariate analysis was also performed using SPSS 13.0 for Windows. An agglomerative hierarchical CA based on the between-groups linkage method and correlation matrix was performed. Details regarding $\mathrm{CA}$ can be found in standard chemometric textbooks

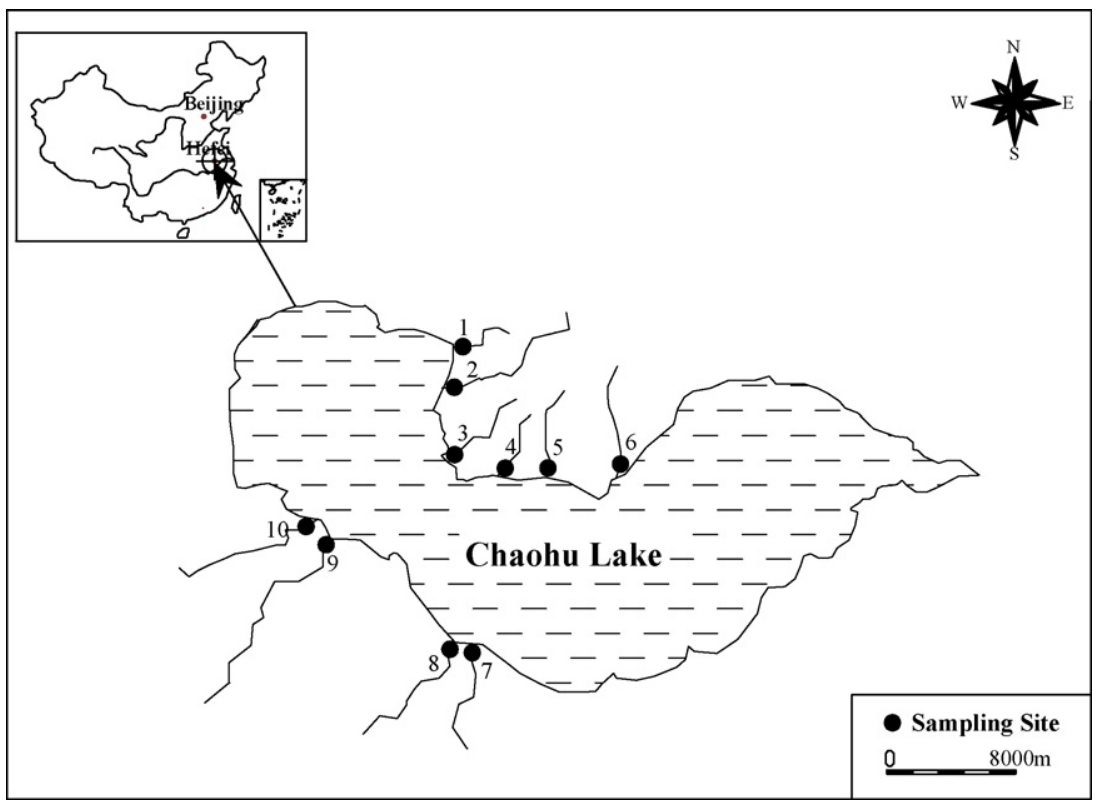

Fig. 1. Sediment sampling stations in the agricultural estuaries of Chaohu Lake Valley, East China. 
[33]. Origin Pro 7.5 was used to plot the experimental data. The results of all indices represent the average of the five sediment columns.

\section{Results and discussion}

\subsection{Spatial-vertical distribution of heavy metal contents in the estuarine sediments}

The distribution of heavy metals showed spatial variability in the estuarine sediments of Chaohu Lake Valley, but most metal contents uniformly increased from the substrate $(25-30 \mathrm{~cm})$ to the surface $(0-5 \mathrm{~cm})$ sediments (Fig. 2). In the ten estuaries, the total concentrations were as follows: Cd, $0.04-1.89 \mathrm{mg} / \mathrm{kg}$, with an average of $0.26 \mathrm{mg} / \mathrm{kg} ; \mathrm{Cr}, 38.12-89.73 \mathrm{mg} / \mathrm{kg}$, with an average of $63.36 \mathrm{mg} / \mathrm{kg}$; $\mathrm{Cu} 15.58-48.34 \mathrm{mg} / \mathrm{kg}$, with an average of $20.40 \mathrm{mg} / \mathrm{kg}$; $\mathrm{Ni}, 12.18-45.51 \mathrm{mg} / \mathrm{kg}$, with an average of $20.06 \mathrm{mg} / \mathrm{kg} ; \mathrm{Pb}, 2.23-43.35 \mathrm{mg} / \mathrm{kg}$, with an average of $10.76 \mathrm{mg} / \mathrm{kg} ; \mathrm{Zn}, 17.81-257.84 \mathrm{mg} / \mathrm{kg}$, with an average of $74.37 \mathrm{mg} / \mathrm{kg}$. There was no apparent vertical variability in the $\mathrm{Cr}$, $\mathrm{Cu}$ and Ni concentrations $(p>0.05)$ in the estuarine sediments, but the $\mathrm{Cd}, \mathrm{Pb}$ and $\mathrm{Zn}$ concentrations were all lowest at the bottom of the cores and highest at the surface. Specifically, the average $\mathrm{Cr}, \mathrm{Cu}$ and $\mathrm{Ni}$ concentrations increased from $0.21,8.05$ and $73.76 \mathrm{mg} / \mathrm{kg}$ to $0.33,17.20$ and $100.22 \mathrm{mg} / \mathrm{kg}$, respectively. The higher concentration of metals at the surface of the sediments indicates that a substantial increase in anthropogenic metal loads has occurred recently [34]. In Chaohu Lake Valley, the land use pattern has been unchanged for more than half a century [22]; therefore, the increased metal content may be the consequence of agricultural
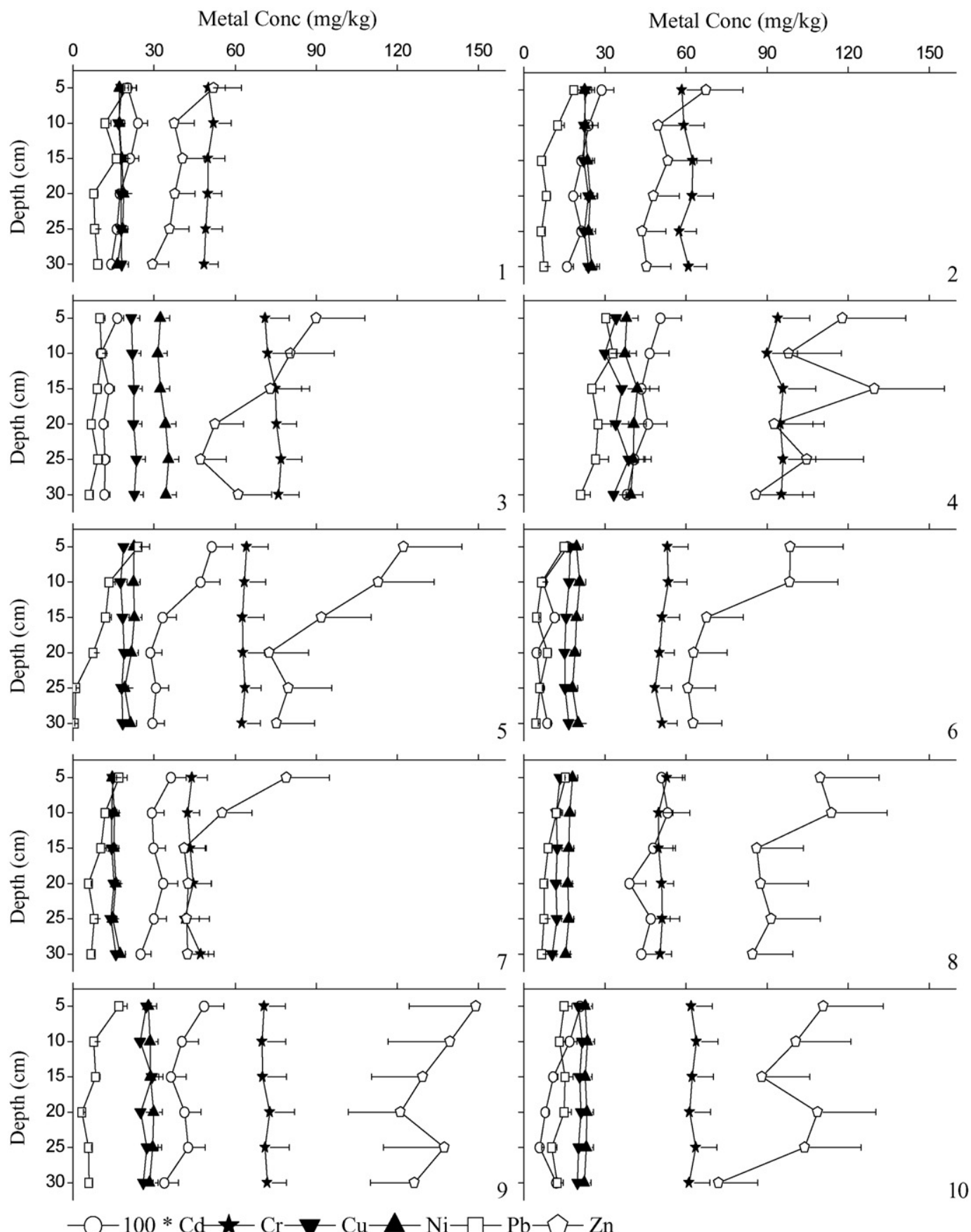

Fig. 2. Total metal concentrations versus sampling site and depth in the estuarine sediments of the agricultural region of Chaohu Lake Valley (from 1 to 10 ). 
intensification, which has developed rapidly in East China since the 1980s.

\subsection{Risk assessment}

In this study, the Risk Assessment Code (RAC) was used to assess the metal concentrations in the sediments from a regulatory perspective. The RAC assesses the potential release of metals in solution based on the percentage of exchangeable and carbonate fractions in sediments. The classification is as follows [35]: metals in exchangeable and carbonate-bound fractions $<1 \%$, no risk; $1-10 \%$, low risk; $11-30 \%$, medium risk; $31-50 \%$, high risk; $\geq 75 \%$, very high risk.

The risk associated with the metals studied in the estuarine sediments of Chaohu Lake Valley has increased in recent years (Fig. 3). In the $0-10 \mathrm{~cm}$ sediment layer, the amount of $\mathrm{Cd}$ in the exchangeable and carbonate fractions ranged from $18.10 \%$ (Changlin River) to $33.60 \%$ (Baishan River), while $\mathrm{Cr}$ ranged from $0.27 \%$ (Changlin
River) to 2.23\% (Jiaozhi River), Cu ranged from 1.08\% (Shengli River) to $4.69 \%$ (Jiaozhi River), Ni ranged from 3.16\% (Xiao River) to $9.24 \%$ (Huatang River), Pb ranged from $8.00 \%$ (Changlin River) to $25.80 \%$ (Baishan River) and Zn ranged from 7.44\% (Shengli River) to $15.97 \%$ (Huatang River). According to the classification of the RAC, the risk associated with $\mathrm{Cd}$ in the sediment cores was moderate in most estuaries, although it was high in some estuaries, while the concentrations of $\mathrm{Pb}$ and $\mathrm{Zn}$ in most estuaries were of medium risk, and those of the other three metals $(\mathrm{Cr}, \mathrm{Cu}$ and $\mathrm{Ni}$ ) posed little to no risk. Sediment contaminants may move into the food chain, particularly if the contaminants are sequestered in bioavailable forms. $\mathrm{Cd}, \mathrm{Pb}$ and $\mathrm{Zn}$ can accumulate in relatively large amounts in plants without any apparent effects, resulting in an inexorable rise in the concentrations of these metals in crops, which could then cause human health problems $[26,36,37]$. Therefore, it is important that heavy metals pollution in the estuarine sediments of the agricultural region of Chaohu Lake Valley should be considered.
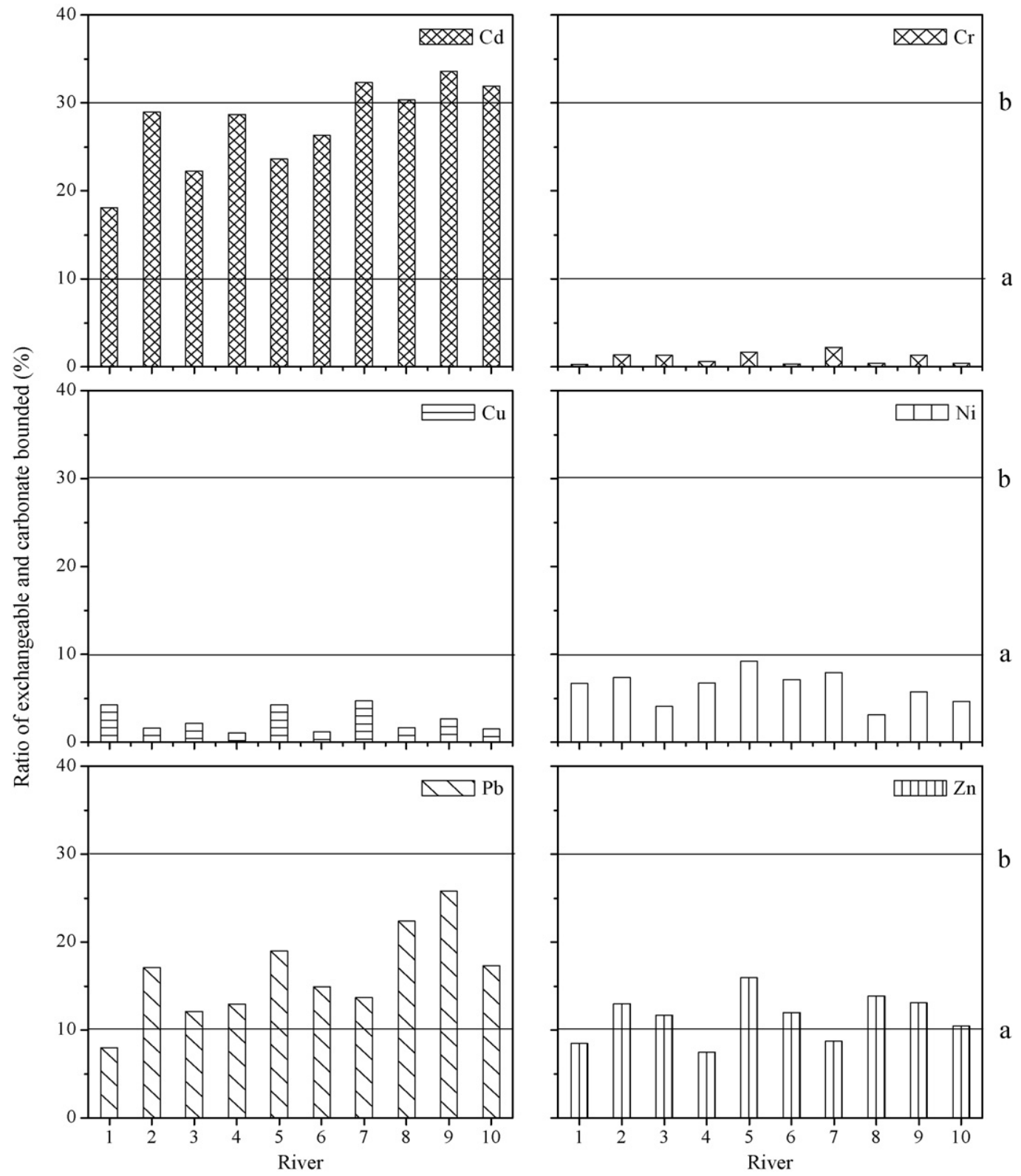

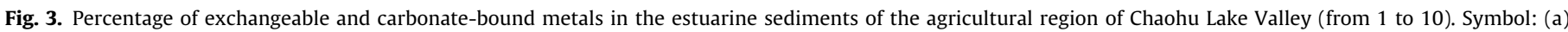
represents low risk and (b) is medium risk. 
Table 1

Pearson's correlation coefficients for heavy metals and sediment physicochemical characteristics $(n=300)$.

\begin{tabular}{lllllll}
\hline & $\mathrm{Cd}$ & $\mathrm{Cr}$ & $\mathrm{Cu}$ & $\mathrm{Ni}$ & $\mathrm{Pb}$ & $\mathrm{Zn}$ \\
\hline $\mathrm{TP}$ & $0.163^{\mathrm{a}}$ & -0.105 & 0.030 & -0.093 & $0.162^{\mathrm{a}}$ & $0.024^{\mathrm{b}}$ \\
$\mathrm{Cd}$ & 1.000 & 0.176 & $0.175^{\mathrm{b}}$ & 0.126 & $0.144^{\mathrm{b}}$ & $0.222^{\mathrm{a}}$ \\
$\mathrm{Cr}$ & 0.176 & 1.000 & $0.804^{\mathrm{a}}$ & $0.937^{\mathrm{a}}$ & $0.534^{\mathrm{b}}$ & $0.295^{\mathrm{b}}$ \\
$\mathrm{Cu}$ & $0.175^{\mathrm{b}}$ & $0.804^{\mathrm{a}}$ & 1.000 & $0.812^{\mathrm{a}}$ & $0.429^{\mathrm{b}}$ & $0.267^{\mathrm{a}}$ \\
$\mathrm{Ni}$ & 0.126 & $0.937^{\mathrm{a}}$ & $0.812^{\mathrm{a}}$ & 1.000 & $0.451^{\mathrm{a}}$ & $0.287^{\mathrm{b}}$ \\
$\mathrm{Pb}$ & $0.144^{\mathrm{b}}$ & $0.534^{\mathrm{b}}$ & $0.429^{\mathrm{b}}$ & $0.451^{\mathrm{a}}$ & 1.000 & $0.120^{\mathrm{a}}$ \\
$\mathrm{Zn}$ & $0.222^{\mathrm{a}}$ & $0.295^{\mathrm{b}}$ & $0.267^{\mathrm{a}}$ & $0.287^{\mathrm{b}}$ & $0.120^{\mathrm{a}}$ & 1.000 \\
\hline
\end{tabular}

a Correlation is significant at the 0.01 level (two-tailed).

b Correlation is significant at the 0.05 level (two-tailed).

\subsection{Correlation analysis of the heavy metal contents and total phosphorus}

The total phosphorus (TP) concentrations in the surface sediments $(0-5 \mathrm{~cm})$ ranged from $304.10 \mathrm{mg} / \mathrm{kg}$ (Changlin River) to $604.00 \mathrm{mg} / \mathrm{kg}$ (Baishan River), and increased from 374.70 to $537.40 \mathrm{mg} / \mathrm{kg}$ on average from the substrate $(25-30 \mathrm{~cm})$ to the surface $(0-5 \mathrm{~cm})$ in the sediments collected from all ten estuaries. The relationship between heavy metal contents and TP was analyzed by Pearson's correlation (Table 1 ). TP was positively correlated with Cd and $\mathrm{Pb}(p \leq 0.01)$, as well as with $\mathrm{Zn}(p \leq 0.05)$. These findings suggest that persistent application of fertilizers in Chaohu Lake Valley may have led to an increase in P content as well as heavy metal accumulation.

The inter-element relationships can provide information regarding heavy metal sources [38]; therefore, the Pearson correlation coefficients of the heavy metals were analyzed (Table 1 ). In the sediments, a high positive correlation $(p \leq 0.01)$ was observed between $\mathrm{Cd}$ and $\mathrm{Zn}, \mathrm{Cr}$ and $\mathrm{Ni}, \mathrm{Cu}$ and other metals (except $\mathrm{Cd}$ and $\mathrm{Pb}), \mathrm{Ni}$ and $\mathrm{Pb}$ and $\mathrm{Pb}$ and $\mathrm{Zn}$. In addition, a significant positive correlation $(p \leq 0.05)$ was observed between $\mathrm{Cd}$ and $\mathrm{Cu}, \mathrm{Cr}$ and $\mathrm{Zn}$, $\mathrm{Ni}$ and $\mathrm{Zn}$ and $\mathrm{Pb}$ and other metals. Finally, no statistically significant correlation was observed between $\mathrm{Cd}$ and $\mathrm{Cr}$ or $\mathrm{Cd}$ and $\mathrm{Ni}$. These results indicate that the metals in the analyzed sediments had different origins or controlling factors.

\subsection{Sources analysis of heavy metals in the estuarine sediments}

\subsubsection{Enrichment factor}

To further elucidate the potential sources of heavy metals in the estuarine sediments of the agricultural region of Chaohu Lake Valley, basic statistics for the EFs of all analyzed metals were evaluated (Table 2). The EF values of $\mathrm{Cd}$ were the highest, reaching 4.96 on average, while the values of $\mathrm{Pb}$ and $\mathrm{Zn}$ were moderate (Mean $=3.68$ and 2.25, respectively). Overall, the EF values of these metals followed the sequence $\mathrm{Cd}>\mathrm{Pb}>\mathrm{Zn}>\mathrm{Cr} \approx \mathrm{Cu} \approx N$. Additionally, the mean and median element EF values revealed that $\mathrm{Cd}, \mathrm{Pb}$ and $\mathrm{Zn}$ enrichment in the sediments had occurred.

Based on a study conducted by Zhang and Liu [20], an EF value between 0.5 and 1.5 suggests that the metal may be entirely from crustal materials or natural weathering processes. However, an EF

Table 2

Descriptive statistics of the enrichment factors of heavy metals in analyzed sediments.

\begin{tabular}{lllr}
\hline Element & Mean & Min & Max \\
\hline $\mathrm{Cd}$ & 4.96 & 0.77 & 36.30 \\
$\mathrm{Cr}$ & 1.25 & 0.60 & 2.77 \\
$\mathrm{Cu}$ & 1.02 & 0.33 & 3.90 \\
$\mathrm{Ni}$ & 1.45 & 0.63 & 4.49 \\
$\mathrm{~Pb}$ & 3.68 & 0.08 & 14.81 \\
$\mathrm{Zn}$ & 2.25 & 0.05 & 11.75 \\
\hline
\end{tabular}

greater than 1.5 suggests that a significant portion of the metal originated from non-crustal or anthropogenic processes. Thus, the results of the present study indicate that $\mathrm{Cd}, \mathrm{Pb}$ and $\mathrm{Zn}$ in the estuarine sediments of the agricultural region of Chaohu Lake Valley had anthropogenic origins, while $\mathrm{Cr}, \mathrm{Cu}$ and $\mathrm{Ni}$ were derived from the crust. These results could be interpreted as the contamination of Chaohu Lake Valley with $\mathrm{Cd}, \mathrm{Pb}$ and $\mathrm{Zn}$, which was not unexpected $[10,39,40]$. Although EF alone cannot precisely distinguish the sources of the heavy metals in the sediments, these factors may be useful indicators of the role of anthropogenic processes in their distribution.

\subsubsection{Cluster analysis}

Real-world examples of regional geochemical surveys have shown that EF is influenced by a number of factors [41]; therefore, the agglomeration schedule of CA based on Pearson's correlation as an amalgamation rule and the squared Euclidean distance as a measure of the proximity between samples were investigated (Table 3). The results obtained by CA are presented by association between groups of variables, with a lower value on the axis representing a more significant association (Fig. 4). In the present study, $\mathrm{Cr}, \mathrm{Cu}$ and $\mathrm{Ni}$ were grouped into one branch, while $\mathrm{Cd}, \mathrm{Pb}$ and $\mathrm{Zn}$ were isolated into other branch. According to CA, two major components were extracted. The first component, which included $\mathrm{Cr}$, $\mathrm{Cu}$ and $\mathrm{Ni}$, may represent the natural source of the sediments. The second component, which included $\mathrm{Cd}, \mathrm{Pb}$ and $\mathrm{Zn}$, likely represents the anthropogenic source.

According to EF and $\mathrm{CA}$, heavy metals ( $\mathrm{Cd}, \mathrm{Pb}$ and $\mathrm{Zn}$ ) that pose a risk have largely enriched in the estuarine sediments of Chaohu Lake Valley during the recent period of agricultural intensification. In fact, land use in the study area is primarily agricultural and has remained fairly constant over the past forty years, while the estuaries are subject to diffuse inputs from agriculture [29]. Rapid agricultural intensification has occurred in East China since the 1980s, which has resulted in the extensive use of fertilizers on farmlands. The widespread use of the main fertilizer used in Chaohu Lake Valley (phosphate) began in the 1960s. As agricultural intensification developed, the amount of phosphate fertilizer usage increased, reaching $0.40 \mathrm{~kg} / \mathrm{km}^{2}$ in the $1980 \mathrm{~s}$ and $2.70 \mathrm{~kg} / \mathrm{km}^{2}$ by 2000 [28]. Phosphate fertilizer used in the study area also contains heavy metals (Cd $2.25 \mathrm{mg} / \mathrm{kg}, \mathrm{Cr} 16.86 \mathrm{mg} / \mathrm{kg}$, Cu $8.84 \mathrm{mg} / \mathrm{kg}$, Ni $7.22 \mathrm{mg} / \mathrm{kg}$, $\mathrm{Pb} 39.83 \mathrm{mg} / \mathrm{kg}$ and $\mathrm{Zn} 161.09 \mathrm{mg} / \mathrm{kg}$ ). Researchers have pointed out that only $10-15 \%$ of applied phosphate fertilizer is absorbed by the crops, while the rest is lost [42]. In addition, an increasing number of machines have been employed in agricultural operations for cultivation, water pumping and harvesting. Because $\mathrm{Pb}$ was previously added to gasoline [43], the use of gasoline-powered machines represents another anthropogenic source of $\mathrm{Pb}$. Furthermore, the

\section{Rescaled Distance Cluster Combine}

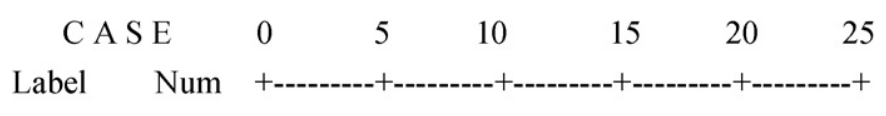

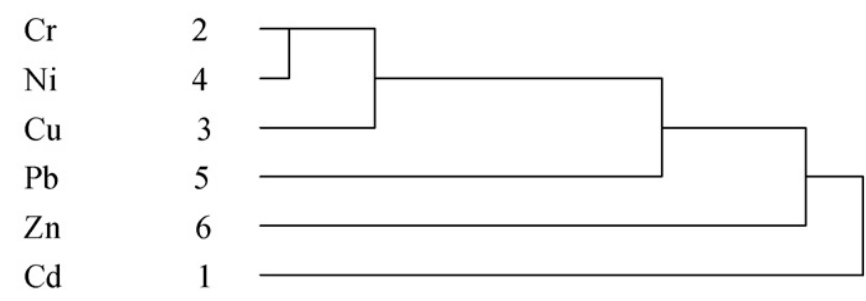

Fig. 4. Dendrogram derived from the hierarchical cluster analysis of heavy metal contents in the analyzed sediments. 
Table 3

Agglomeration schedule of the cluster analysis based on the correlation coefficients.

\begin{tabular}{lllllll}
\hline \multirow{2}{*}{ Stage } & \multicolumn{2}{l}{ Cluster combined } & & Coefficients & & \multicolumn{2}{l}{ Stage cluster fist appears } & \multirow{2}{*}{ Next stage } \\
\cline { 2 - 3 } \cline { 6 - 7 } & Cluster 1 & Cluster 2 & & & Cluster 1 & Cluster 2 \\
\hline 1 & $2 \mathrm{Cr}$ & $4 \mathrm{Ni}$ & 0.937 & 0 & 0 & 2 \\
2 & $2 \mathrm{Cr}$ & $3 \mathrm{Cu}$ & 0.808 & 1 & 0 & 3 \\
3 & $2 \mathrm{Cr}$ & $5 \mathrm{~Pb}$ & 0.471 & 0 & 2 & 4 \\
4 & $2 \mathrm{Cr}$ & $6 \mathrm{Zn}$ & 0.242 & 0 & 3 & 5 \\
5 & $1 \mathrm{Cd}$ & $2 \mathrm{Cr}$ & 0.149 & 0 & 4 & 0 \\
\hline
\end{tabular}

results of the EF and CA analysis are consistent with the vertical distribution of the heavy metals. Taken together, these findings indicate that heavy metal accumulation has occurred intensively in the study area during agricultural intensification. Similar findings have been found in other studies [26,34,44]. Therefore, the results of this study clearly demonstrate that agricultural intensification has resulted in an increasing use of phosphate fertilizer and is the main source of metal accumulation in the estuarine sediments of the agricultural region of Chaohu Lake Valley.

\section{Conclusion}

The intensive use of phosphate fertilizer has resulted in dramatic increases in the concentrations of metals in the estuarine sediments of Chaohu Lake Valley. The contents of $\mathrm{Cd}, \mathrm{Pb}$ and $\mathrm{Zn}$ were higher in the surface sediments, and decreased with sediment depth. According to the RAC, the risk of $\mathrm{Cd}$ was medium to high in all estuaries, while the concentrations of $\mathrm{Pb}$ and $\mathrm{Zn}$ in most estuaries were of medium risk. Based on the EF values of each element studied, the selected estuaries were found to have relatively high concentrations of $\mathrm{Cd}, \mathrm{Pb}$ and $\mathrm{Zn}$, while $\mathrm{Cr}, \mathrm{Cu}$ and $\mathrm{Ni}$ were present in lower levels. The application of CA revealed that natural weathering was the source of $\mathrm{Cr}, \mathrm{Cu}$ and $\mathrm{Ni}$, while $\mathrm{Cd}, \mathrm{Pb}$ and $\mathrm{Zn}$ were found to be of anthropogenic origin. This information could be useful in developing effective management strategies to control pollution in Chaohu Lake Valley.

\section{Acknowledgements}

This research was supported by the National Basic Research Program of China (No. 2006CB403306) and the Study on the Withholding Characteristics of Pollutants from Non-point Sources in Complex Landscapes (No. 50679087).

\section{References}

[1] S.B. Griscom, N.S. Fisher, S.N. Luoma, Geochemical influences on assimilation of sediment-bound metals in clams and mussels, Environ. Sci. Technol. 34 (2000) 91-99.

[2] Y.M. N'Guessan, J.L. Probst, T. Bur, A. Probst, Trace elements in stream bed sediments from agricultural catchments (Gascogne region, S-W France): where do they come from? Sci. Total Environ. 409 (2009) 2939-2952.

[3] C.J. Buggy, J.M. Tobin, Seasonal and spatial distribution of metals in surface sediment of an urban estuary, Environ. Pollut. 155 (2008) 308-319.

[4] E. Leorri, A. Cearreta, M.J. Irabien, I. Yusta, Geochemical and microfaunal proxies to assess environmental quality conditions during the recovery process of a heavily polluted estuary: the Bilbao estuary case (N. Spain), Sci. Total Environ. 396 (2008) 12-27.

[5] M. Rival Da Silya, M. Lamotte, O.F.X. Donard, E.J. Soriano-Sierra, M. Robert, Metal contamination in surface sediments of mangroves, lagoons and Southern Bay in Florianopolis Island, Environ. Technol. 17 (1996) 1035-1046.

[6] A.P. Karageorgis, A.I. Sioulas, C.L. Anagnostou, Use of surface sediments in Pagassitikos Gulf, Greece, to detect anthropogenic influence, Geo-Mari. Lett. 22 (2002) 200-211.

[7] A.P. Mucha, M.T.S.D. Vasconcelos, A.A. Bordalo, Macrobenthic community in the Douro Estuary: relations with trace metals and natural sediment characteristics, Environ. Pollut. 121 (2003) 169-180.

[8] H. Li, A.P. Davis, Heavy metal capture and accumulation in bioretention media, Environ. Sci. Technol. 42 (2008) 5247-5253.

[9] M. Frignani, L.G. Bellucci, Heavy metals in marine coastal sediments: assessing sources, fluxes, history and trends, Annali di Chimica 94 (2004) 1-8.
[10] J.N. Quinton, J.A. Catt, Enrichment of heavy metals in sediment resulting from soil erosion on agricultural fields, Environ. Sci. Technol. 41 (2007) 3495-3500.

[11] A. Navas, J. Machin, Spatial distribution of heavy metals and arsenic in soils of Aragon (northeast Spain): controlling factors and environmental implications, Appl. Geochem. 17 (2002) 961-973.

[12] R. Burt, M.A. Wilson, M.D. Mays, C.W. Lee, Major and trace elements of selected pedons in the USA, J. Environ. Qual. 32 (2003) 2109-2121.

[13] F.A. Vega, E.F. Covelo, M.L. Andrade, P. Marcet, Relationship between heavy metal content and soil properties in minesoils, Anal. Chim. Acta 524 (2004) 141-150.

[14] C. Liu, J.A. Jay, T.E. Ford, Evaluation of environmental effects on metal transport from capped contaminated sediment under conditions of submarine groundwater discharge, Environ. Sci. Technol. 35 (2001) 4549-4555.

[15] G. Du Laing, J. Rinklebe, B. Vandecasteele, E. Meers, F.M.G. Tack, Trace meta behaviour in estuarine and riverine floodplain soils and sediments: a review, Sci. Total Environ. 407 (2009) 3977-3985.

[16] H. Zhang, B.Q. Shan, Historical records of heavy metal accumulation in sediments and the relationship with agricultural intensification in the Yangtze-Huaihe region, China, Sci. Total Environ. 399 (2008) 113-120.

[17] N. Zheng, Q.H. Wang, Z.Z. Liang, D.M. Zhen, Characterization of heavy meta concentrations in the sediments of three freshwater rivers in Huludao City, Northeast China, Environ. Pollut. 154 (2008) 135-142.

[18] K.C. Jones, A.E. Johnston, Cadmium in cereal grain and herbage from long-term experimental plots at Rothamsted, UK, Environ. Pollut. 57 (1989) 199-216.

[19] E.F. Covelo, F.A. Vega, M.L. Andrade, Simultaneous sorption and desorption of $\mathrm{Cd}, \mathrm{Cr}, \mathrm{Cu}, \mathrm{Ni}, \mathrm{Pb}$, and $\mathrm{Zn}$ in acid soils II. Soil ranking and influence of soil characteristics, J. Hazard. Mater. 147 (2007) 862-870.

[20] J. Zhang, C.L. Liu, Riverine composition and estuarine geochemistry of particulate metals in China-weathering features, anthropogenic impact and chemical fluxes, Estuar. Coast. Shelf Sci. 54 (2002) 1051-1070.

[21] Q.Y. Tu, D.X. Gu, C.Q. Yin, Z.R. Xu, J.Z. Han, The Chao Lake-study on Eutrophication, University of Science and Technology of China Press, Hefei, 1991.

[22] D.M. Qin, X.H. Chen, The agriculture development of Yangtze-Huaihe region in six dynasties period, Agricult. Hist. China 15 (1996) 12-19.

[23] M.G. Paoletti, M. Giampietro, H. Chunru, G. Pastore, S.G.F. Bukkens, Studying agricultural intensification and sustainability in PR China, Crit. Rev. Plant Sci. 18 (1999) 257-259.

[24] F. Gavi, N.T. Basta, W.R. Raun, Wheat grain cadmium as affected by long-term fertilization and soil acidity, J. Environ. Qual. 26 (1997) 265-272.

[25] S.S. Huang, Q.L. Liao, M. Hua, X.M. Wu, K.S. Bi, C.Y. Yan, Survey of heavy metal pollution and assessment of agricultural soil in Yangzhong district, Jiangsu Province, China, Chemosphere 67 (2007) 2148-2155.

[26] R. Lambert, C. Grant, S. Sauve, Cadmium and zinc in soil solution extracts following the application of phosphate fertilizers, Sci. Total Environ. 378 (2007) 293-305.

[27] G.W. Zhu, B.Q. Qin, L. Zhang, L.C. Luo, Geochemical forms of phosphorus in sediments of three large, shallow lakes of China, Pedosphere 16 (2006) 726-734

[28] H. Zhang, B.Q. Shan, Historical distribution and partitioning of phosphorus in sediments in an agricultural watershed in the Yangtze-Huaihe region, China, Environ. Sci. Technol. 42 (2008) 2328-2333.

[29] S.M. Wang, H.S. Dou, Record of Chinese Lakes, Science Press, Beijing, 1998.

[30] S.D. Bao, Soil and Agricultural Chemical Analysis, Chinese Agricultural Publisher, Beijing, 2000.

[31] A. Tessier, P.G.C. Campbell, M. Bisson, Sequential extraction procedure for the speciation of particulate trace metals, Anal. Chem. 51 (1979) 844-851.

[32] J. Hlavay, K. Polyak, Chemical speciation of elements in sediment samples collected at Lake Balaton, Microchem. J. 58 (1998) 281-290.

[33] R.G. Brereton, Chemometrics: Data Analysis for the Laboratory and Chemical Plant, John Wiley \& Sons, West Sussex, 2003.

[34] I. Sondi, L. Sonja, M. Juracic, E. Prohic, Mechanisms of land-sea interactions-the distribution of metals and sedimentary organic matter in sediments of a riverdominated Mediterranean karstic estuary, Estuar. Coast. Shelf Sci. 80 (2008) $12-20$

[35] K.P. Singh, D. Mohan, V.K. Singh, A. Malik, Studies on distribution and fractionation of heavy metals in Gomti river sediments-a tributary of the Ganges, India, J. Hydrol. 312 (2005) 14-27.

[36] D. Fitamo, F. Itana, M. Olsson, Total contents and sequential extraction of heavy metals in soils irrigated with wastewater, Akaki, Ethiopia, Environ. Manage. 39 (2007) 178-193.

[37] L.Y.L. Zhao, R. Schulin, B. Nowack, The effects of plants on the mobilization of $\mathrm{Cu}$ and $\mathrm{Zn}$ in soil columns, Environ. Sci. Technol. 41 (2007) 2770-2775. 
[38] S. Dragovic, N. Mihailivic, B. Gajic, Heavy metals in soils: distribution, relationship with soil characteristics and radionuclides and multivariate assessment of contamination sources, Chemosphere 72 (2008) 491-495.

[39] I.K. Iksandar, D.R. Keeney, Concentration of heavy metals in sediment cores from selected Wisconsin lakes, Environ. Sci. Technol. 8 (1974) 165-170.

[40] E.S. Pilkington, L.J. Warren, Determination of heavy metal distribution in marine sediments, Environ. Sci. Technol. 13 (1979) 295-299.

[41] C. Reimann, P. Caritat, Distinguishing between natural and anthropogenic sources for elements in the environment: regional geochemical surveys versus enrichment factors, Sci. Total Environ. 337 (2005) 91-107.
[42] E. Bulut, A. Aksoy, Impact of fertilizer usage on phosphorus loads to Lake Uluabat, Desalination 226 (2008) 289-297.

[43] S.C. Wong, X.D. Li, G. Zhang, S.H. Qi, Y.S. Min, Heavy metals in agricultural soils of the Pearl River Delta, South China, Environ. Pollut. 119 (2002) 33-44.

[44] C.W. Tang, C.C. Ip, G. Zhang, P.K. Shin, P.Y. Qian, X.D. Li, The spatial and temporal distribution of heavy metals in sediments of Victoria Harbour, Hong Kong, Mar. Pollut. Bull. 57 (2008) 816-825. 